\title{
Percutaneous endoscopic unilateral laminotomy and bilateral decompression under 3D real-time image-guided navigation for spinal stenosis in degenerative lumbar kyphoscoliosis patients: an innovative preliminary study
}

Tsung-Yu Ho ${ }^{1 \dagger}$, Chung-Wei Lin ${ }^{1 \dagger}$, Chien-Chun Chang ${ }^{1,2,3,4^{*}}$ (D), Hsien-Te Chen ${ }^{1,2,5^{*}}$, Yen-Jen Chen ${ }^{1,2,6}$, Yuan-Shun Lo ${ }^{1,2}$, Pan-Hsuan Hsiao ${ }^{1,2}$, Po-Chen Chen ${ }^{7}$, Chih-Sheng Lin ${ }^{3,4}$ and Hsi-Kai Tsou ${ }^{8,9}$

\begin{abstract}
Background: The aim of this study is to introduce a new method of percutaneous endoscopic decompression under 3D real-time image-guided navigation for spinal stenosis in degenerative kyphoscoliosis patients without instability or those who with multiple comorbidities. Decompression alone using endoscope for kyphoscoliosis patient is technical demanding and may result in unnecessary bone destruction leading to further instability. The Oarm/StealthStation system is popular for its ability to provide automated registration with intraoperative, postpositioning computed tomography $(\mathrm{CT})$ which results in superior accuracy in spine surgery.

Methods: In this study, we presented four cases. All patients were over seventy years old female with variable degrees of kyphoscoliosis and multiple comorbidities who could not endure major spine fusion surgery. Percutaneous endoscopic unilateral laminotomy and bilateral decompression under 3D real-time image-guided navigation were successfully performed. Patients' demographics, image study parameters, and outcome measurements including pre- and post-operative serial Visual analog scale (VAS), and Oswestry Disability Index (ODI) were well documented. The follow-up time was 1 year.

(Continued on next page)
\end{abstract}

\footnotetext{
* Correspondence: ccchangmd@gmail.com; bonekid1@gmail.com

${ }^{\dagger}$ Tsung-Yu Ho and Chung-Wei Lin are co-first authors and contributed equally to the work.

'Department of Orthopedic Surgery, China Medical University Hospital, China Medical University, No. 2, Xueshi Rd., North Dist, Taichung City 404, Taiwan Full list of author information is available at the end of the article
}

(c) The Author(s). 2020 Open Access This article is licensed under a Creative Commons Attribution 4.0 International License, which permits use, sharing, adaptation, distribution and reproduction in any medium or format, as long as you give appropriate credit to the original author(s) and the source, provide a link to the Creative Commons licence, and indicate if changes were made. The images or other third party material in this article are included in the article's Creative Commons licence, unless indicated otherwise in a credit line to the material. If material is not included in the article's Creative Commons licence and your intended use is not permitted by statutory regulation or exceeds the permitted use, you will need to obtain permission directly from the copyright holder. To view a copy of this licence, visit http://creativecommons.org/licenses/by/4.0/ The Creative Commons Public Domain Dedication waiver (http://creativecommons.org/publicdomain/zero/1.0/) applies to the data made available in this article, unless otherwise stated in a credit line to the data. 
(Continued from previous page)

Results: Pre- and post-operative MRI showed average dural sac cross sectional area (DSCSA) improved from 81.62 (range 67.34-89.07) to 153.27 (range 127.96-189.73). Preoperative neurological symptoms including radicular leg pain improved postoperatively. The mean ODI (\%) were 85 (range 82.5-90) at initial visit, 35.875 (range 25-51) at 1 month post-operatively, 26.875 (range 22.5-35) at 6 months post-operatively and 22.5 (range 17.5-30) at 12 months post-operatively $(p<0.05)$. The mean VAS score were 9 (range 8-10) at initial visit, 2.25 (range 2-3) at 1 month postoperatively, 1.75 (range 1-2) at 6 months post-operatively and 0.25 (range $0-1$ ) at 12 months post-operatively ( $p<$ 0.05). There was no surgery-related complication.

Conclusions: To the best of our knowledge, this is the first preliminary study of percutaneous endoscopic laminotomy under O-arm navigation with successful outcomes. The innovative technique may serve as a promising solution in treating spinal stenosis patients with lumbar kyphoscoliosis and multiple comorbidities.

Keywords: Navigation, Spinal stenosis, Lumbar spine, Endoscopic surgery, Kyphoscoliosis, Decompression alone

\section{Background}

With aging of the population, spinal stenosis with degenerative kyphoscoliosis has become an increasingly common condition. Lumbar spinal stenosis with or without degenerative spondylolisthesis is a pathologic condition that is often observed in the geriatric population, which is the spinal canal narrowing caused by redundant ligamentum flavum and hypertrophic facet joints and osteophytes, and may present with clinical symptoms such as radicular leg pain or neurogenic claudication $[1,2]$.

Recent studies have suggested that nonsurgical treatment may not be as effective $[3,4]$. The current medical evidence continues to support the role of surgery over non-operative therapies for symptomatic stenosis patients associated with spondylolisthesis [5]. The prospective, randomized, multicenter Spine Patient Outcomes Research Trial (SPORT) also suggests that patients who are treated surgically present with a significantly greater improvement in pain, function, satisfaction, and self-rated progress over 8 years compared to patients treated non-operatively [6-8].

Various studies have evaluated the efficacy of decompression alone versus decompression with fusion for this condition, but the results are still controversial [9-13]. Decompression alone have shown similar results in clinical outcomes compared to decompression with fusion $[9,11,13]$. Open discectomy with laminotomy or laminectomy alone has been considered as standard treatment for lumbar spinal stenosis without instability during the last decades [14]. Percutaneous endoscopic decompression which features minimal amount of tissue injury, less blood loss and a faster recovery serves as a solution to patients with multiple comorbidities. However, decompression alone using endoscope for kyphoscoliosis patient is technically demanding and may result in unnecessary bone destruction leading to iatrogenic instability $[15,16]$.

Considerable advances in $3 \mathrm{D}$ real-time image navigation have changed the nature of spine surgery $[17,18]$.
The advantages with the use of 3D real-time image navigation include multiple level images in a single sequence and accuracy [19]. With the assistance of 3D real-time image navigation, the depth and location of endoscope trocar, high speed burr and relevant anatomy could be instantly demonstrated on the monitor during the procedure. The amount of bony structure removed could be well-visualized on the monitor. Thus, the risk of inadequate decompression and unnecessary bone destruction with iatrogenic instability could be thus limited. This is the first study reporting endoscopic decompression surgery under $3 \mathrm{D}$ real-time image navigation to treat degenerative kyphoscoliosis patients.

The purpose of this study is to describe a novel method which combined full-endoscopic spinal decompression and 3D real-time image navigation. The preliminary result shows adequate and precise decompression without leading to iatrogenic instability when treating spinal stenosis in degenerative kyphoscoliosis patients.

\section{Methods \\ Patient enrollment}

Four kyphoscoliosis patients diagnosed with lumbar spinal stenosis between March 2017 and January 2018 were enrolled in this study (Fig. 1). Our inclusion criteria were as follows: lumbar central or lateral recess spinal stenosis with kyphoscoliosis, radicular leg pain or claudication refractory to conservative treatment for at least 6 months, absence of spinal instability confirmed by dynamic radiographs. Instability is considered as of sagittal angulation values $>15^{\circ}$, values in millimeters of translation on the sagittal plane (or coronal plane) $>4 \mathrm{~mm}$ or shift $>15 \%$ of the inferior vertebral endplate measure. We excluded patients with lumbar foraminal spinal stenosis, spondylolisthesis, compression or burst fracture, infection, tumor, previous lumbar surgery. The participants included four women with an average age of 80.25 years (range, 


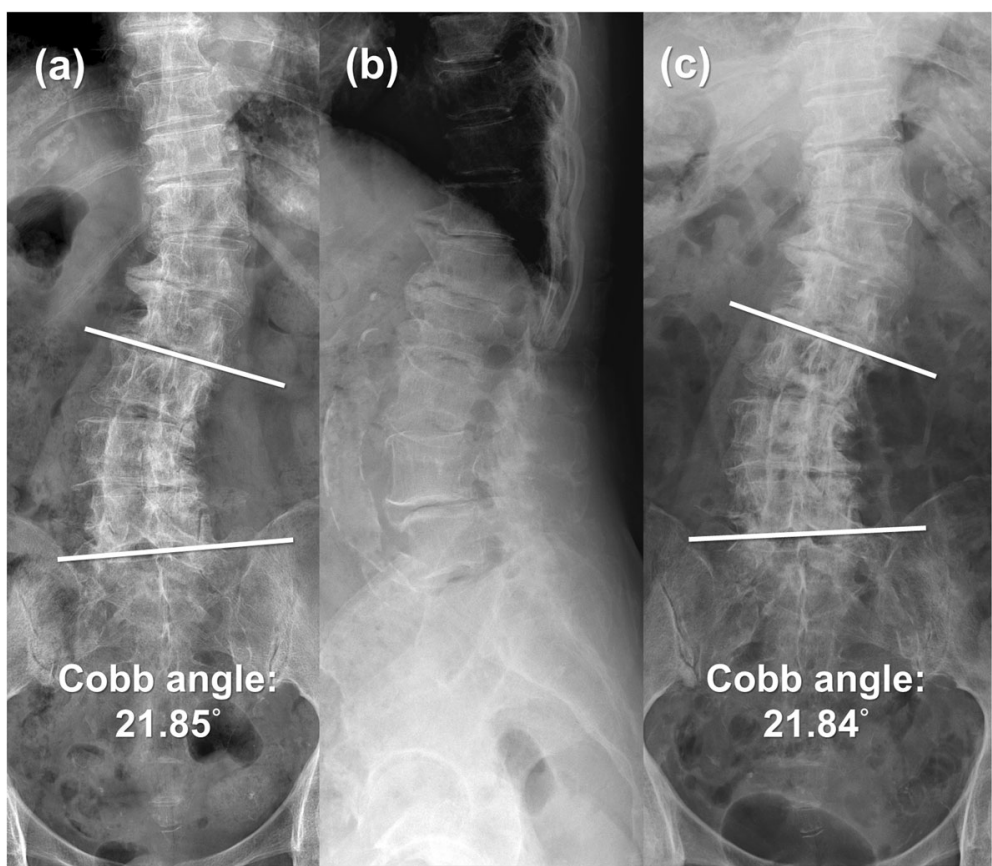

Fig. 1 a Preoperative AP X-ray shows $21.85^{\circ}$ Cobb angle scoliosis from L3-L5. b Preoperative lateral X-ray reveals mild spondylolisthesis over L4L5. c Postoperative AP X-ray shows $21.84^{\circ}$ Cobb angle scoliosis from L3-L5. a, c Serial images demonstrate no progression of the scoliosis

73-86 years). The average Body Mass Index (BMI) was 24.58 (range 19.94-28.36). The affected levels ranged from L2-S1. The operation level was decided according to clinical presentation and MRI findings. As for the degree of spinal deformity, data were summarized in Table 1 According to Schwab Classification [20].

\section{Outcome evaluation}

Radiology outcome measurement including serial radiographs (Fig. 1) and dural sac cross sectional area (DSCSA) on MRI were well documented (Fig. 2) (Table 2). As for the clinical outcome evaluation, the Oswestry Disability index (\%) (ODI), Visual analogue scale (VAS) were collected at the initial visit and at

Table 1 Profiles of Patient with Kyphoscoliosis

\begin{tabular}{|c|c|c|c|c|}
\hline & Case 1 & Case 2 & Case 3 & Case 4 \\
\hline Age (years) & 73 & 86 & 82 & 80 \\
\hline BMI $\left(\mathrm{kg} / \mathrm{m}^{2}\right)$ & 28.36 & 23.37 & 19.94 & 26.63 \\
\hline Comorbidities & $\begin{array}{l}\text { Diabetes Mellitus } \\
\text { Chronic Kidney Disease } \\
\text { Stagelll } \\
\text { Chronic Obstructive } \\
\text { Pulmonary Disease }\end{array}$ & $\begin{array}{l}\text { Paroxysmal atrial } \\
\text { fibrillation } \\
\text { Hypertension } \\
\text { Diabetes Mellitus } \\
\text { Chronic Kidney } \\
\text { Disease Stagell }\end{array}$ & $\begin{array}{l}\text { Chronic Kidney Disease } \\
\text { Stagelll } \\
\text { Dementia }\end{array}$ & $\begin{array}{l}\text { Hypertension } \\
\text { Diabetes Mellitus } \\
\text { Congestive Heart } \\
\text { Failure }\end{array}$ \\
\hline Operation Time (minutes) & 272 & 315 & 154 & 233 \\
\hline \multicolumn{5}{|l|}{ Schwab Classification for Adult Spinal Deformity } \\
\hline Type and Location of Deformity & $\begin{array}{l}\text { TypeV Lumbar Major } \\
\text { Curve }\end{array}$ & $\begin{array}{l}\text { TypeV Lumbar Major } \\
\text { Curve }\end{array}$ & $\begin{array}{l}\text { TypeV Lumbar Major } \\
\text { Curve }\end{array}$ & $\begin{array}{l}\text { TypeV Lumbar Major } \\
\text { Curve }\end{array}$ \\
\hline $\begin{array}{l}\text { Lordosis Modifier: Sagittal Cobb angle from T12 } \\
\text { to S1 }\end{array}$ & 20.36 degrees & 20.31 degrees & 21.14 degrees & 21.6 degrees \\
\hline $\begin{array}{l}\text { Subluxation Modifier: Frontal or Sagittal Plane } \\
\text { (Anterior or Posterior), Maximum Value }\end{array}$ & $\begin{array}{l}++ \text { Frontal subluxation } \\
16 \mathrm{~mm}(>7 \mathrm{~mm})\end{array}$ & $\begin{array}{l}\text { +Frontal subluxation } \\
6 \mathrm{~mm}(1-6 \mathrm{~mm})\end{array}$ & $\begin{array}{l}\text { ++ Frontal subluxation } \\
9.4 \mathrm{~mm}(>7 \mathrm{~mm})\end{array}$ & $\begin{array}{l}\text { + Frontal subluxation } \\
5.53 \mathrm{~mm}(1-6 \mathrm{~mm})\end{array}$ \\
\hline $\begin{array}{l}\text { Global Balance Modifier: Sagittal Offset from } \\
\text { Posterior Superior Corner S1 }\end{array}$ & Positive: $7.98 \mathrm{~cm}$ & Positive: $7.13 \mathrm{~cm}$ & Positive: $7.01 \mathrm{~cm}$ & Positive: $4.63 \mathrm{~cm}$ \\
\hline
\end{tabular}




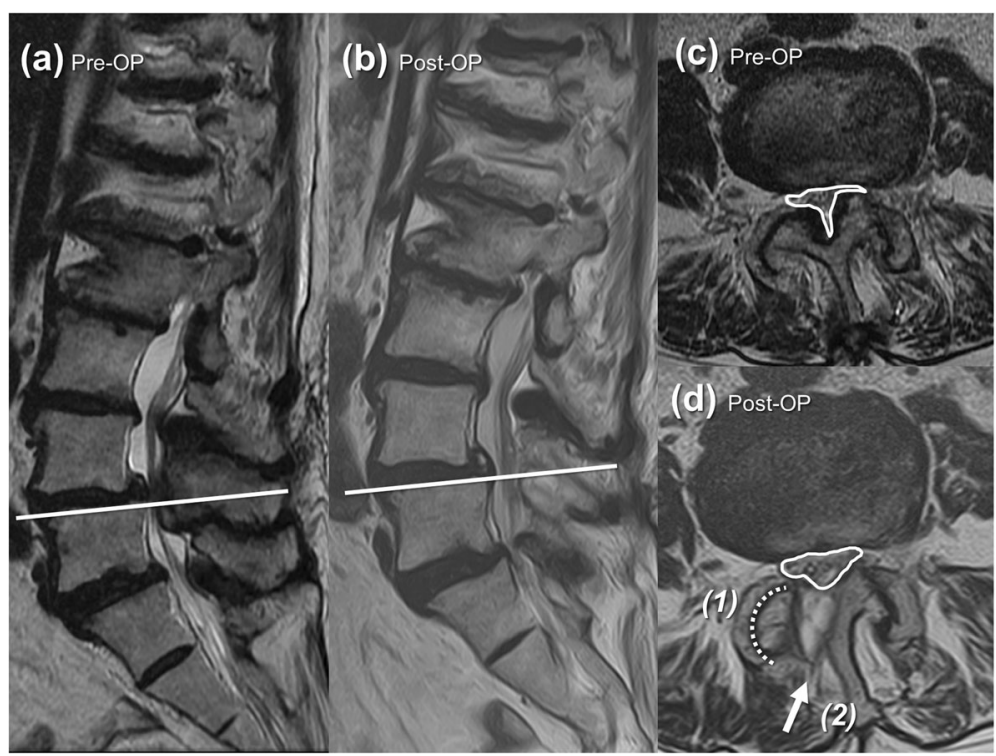

Fig. 2 a Preoperative sagittal section of T2WI MRI shows severe stenosis over L4-L5. b Postoperative sagittal section of T2WI MRI shows stenosis being relieved with intact posterior elements. The decompression level (White line) on axial section of T2WI MRI is shown in (c) and (d). Comparing c preoperative and $\mathbf{d}$ postoperative T2WI axial section MRI, dura sac cross-sectional area (DSCSA) increases significantly after endoscopic laminotomy at L4-5 under O-arm navigation (1) without any facet joints damage, via (2) interlaminar approach

1 month, 6 months and 12 months post-operatively (Table 3).

\section{Statistical analyses}

Statistical Analyses were performed using SPSS for Windows, version 24 (SPSS Inc., Armonk, NY). The Friedman two-way analysis of variance (ANOVA) by ranks test was used as a non-parametric test. A $p<$ 0.05 was considered statistically significant.

\section{Navigation system and instruments}

The O-arm/StealthStation system (Medtronic Inc., Minneapolis, MN, USA), a 3D real-time image-guided navigation system, is popular for its ability to provide automated registration with intraoperative, postpositioning computed tomography (CT). With SureTrak II Universal Tracker (Medtronic Inc., Minneapolis, MN, USA) attached to the endoscope instrument, the depth and position of the endoscopic working channel could be observed in real-time fashion on the O-arm/StealthStation monitor.
The Vertebris ${ }^{\circ}$ Spine Endoscope system (Richard and Wolf, Knittlingen, Germany) features high-resolution endoscope with a $6.9 \times 5.6 \mathrm{~mm}$ diameter and a $4.1 \mathrm{~mm}$ intraendoscopic working channel. The angle of vision is $25^{\circ}$. The working sleeve has an $8.0 \mathrm{~mm}$ outer diameter and a beveled opening, which enable visual and working fields creation in an area with a clear, anatomically preformed cavity.

Surgitron, a high-voltage bipolar probe (Ellman Innovations, New York, USA), is well-known for pinpoint coagulation in a wet field with simultaneously minimal burning or charring of soft tissue. The thermocoagulation device aims to maximized hemorrhage control and thus improves the visibility of the operative field.

\section{Surgical technique \\ Patient preparation}

The surgery was conducted under general anesthesia. The patient was positioned prone on a well cushioned and supportive radiolucent table with the abdomen

Table 2 Patient Radiology Results

\begin{tabular}{llll}
\hline & Operation Level & Pre-OP DSCSA $\left(\mathbf{m m}^{2}\right)$ & Post-OP DSCSA $\left(\mathbf{m m}^{\mathbf{2}}\right)$ \\
\hline Case $\mathbf{1}$ & $\mathrm{L} 3 / \mathrm{L} 4$ & 89.07 & 189.73 \\
Case $\mathbf{2}$ & $\mathrm{L} 4 / \mathrm{L} 5$ & 84.39 & 143.05 \\
Case 3 & $\mathrm{~L} 2 / \mathrm{L} 3$ & 85.68 & 152.34 \\
Case $\mathbf{4}$ & $\mathrm{L} / \mathrm{L} 4$ & 67.34 & 127.96
\end{tabular}

DSCSA Dural Sac Cross Sectional Area, Pre-OP Preoperative, Post-OP Postoperative 
Table 3 Patient Clinical Results

\begin{tabular}{|c|c|c|c|c|c|c|c|c|c|}
\hline & Diagnosis & Pre-C & & Post-OP & & & & & \\
\hline & & $\overline{\text { ODI }}$ & $\overline{\text { VAS }}$ & $\begin{array}{l}\text { ODI } \\
1 \text { Month }\end{array}$ & $\begin{array}{l}\text { VAS } \\
1 \text { Month }\end{array}$ & $\begin{array}{l}\text { ODI } \\
6 \text { Month }\end{array}$ & $\begin{array}{l}\text { VAS } \\
6 \text { Month }\end{array}$ & $\begin{array}{l}\text { ODI } \\
12 \text { Month }\end{array}$ & $\begin{array}{l}\text { VAS } \\
12 \text { Month }\end{array}$ \\
\hline Case 1 & Kyphoscoliosis with Spinal Stenosis L3-L4 & 87.5 & 9 & 25 & 3 & 22.5 & 1 & 17.5 & 1 \\
\hline Case 2 & Kyphoscoliosis with Spinal Stenosis L3/L4/L5 & 82.5 & 10 & 35 & 2 & 25 & 2 & 20 & 0 \\
\hline Case 3 & Kyphoscoliosis with Spinal Stenosis L2/L3/L4 & 90 & 9 & 51 & 2 & 25 & 2 & 22.5 & 0 \\
\hline Case 4 & Kyphoscoliosis with Spinal Stenosis L3/L4 & 80 & 8 & 32.5 & 2 & 35 & 2 & 30 & 0 \\
\hline
\end{tabular}

VAS Visual Analogue Scale, ODI Oswestry Disability index, Pre-OP Preoperative, Post-OP Postoperative

hanging free. Bilateral knees were flexed to over 90 degrees as possible for the opening of interlaminar space. Back skin was then well prepared and draped.

\section{Reference pin insertion and image acquisition}

First, we made a small incision over the iliac crest. We inserted the reference pin through the cannula, and used an impactor to nail the pin into the bone until the tap cap bottoms out on the cannula. Then we removed the tap cap and cannula from the pin, placed the spine reference on the pin and rotated the assembly to lock the frame in place.

The spinal segment of interest was scanned using the Oarm navigation and the images were automatically registered to the Stealth Station. All the navigational instruments were registered.

\section{$3 D$ real-time image-navigated percutaneous endoscopic decompression}

Interlaminar approach was chosen. The skin incision was made under $\mathrm{O}$-arm navigation, which was under the spinal laminal junction. A dilator, $8.0 \mathrm{~mm}$ in outer diameter, was bluntly inserted to the edge of the interlaminar window. Then, an operative sleeve with a beveled opening was directed towards the ligamentum flavum. After attaching the SureTrak ${ }^{\circ}$ II Universal Tracker to the Vertebris $^{\bullet}$ Spine Endoscope (Fig. 3), the endoscope was inserted into the working channel (Fig. 3).

After introduction of the endoscope, the bony boundaries of superior lamina, inferior lamina and facet joint were identified and the soft tissues were removed with bipolar probe, punch and forceps. To broaden the working space, a minimal bone resection was made from medial to lateral. $3-4 \mathrm{~mm}$ of bone around superior and inferior lamina was removed with a diamond burr. Then, the approach proceeded to the superior articular process, creating space for lateral recess decompression. The depth and location of the bony landmark could be well visualized through the O-arm navigation system (Figs. 4 and 5). The $\mathrm{O}$-arm navigation system offered the real-time images as a warning sign before the facet joint was violated, which prevented the spinal

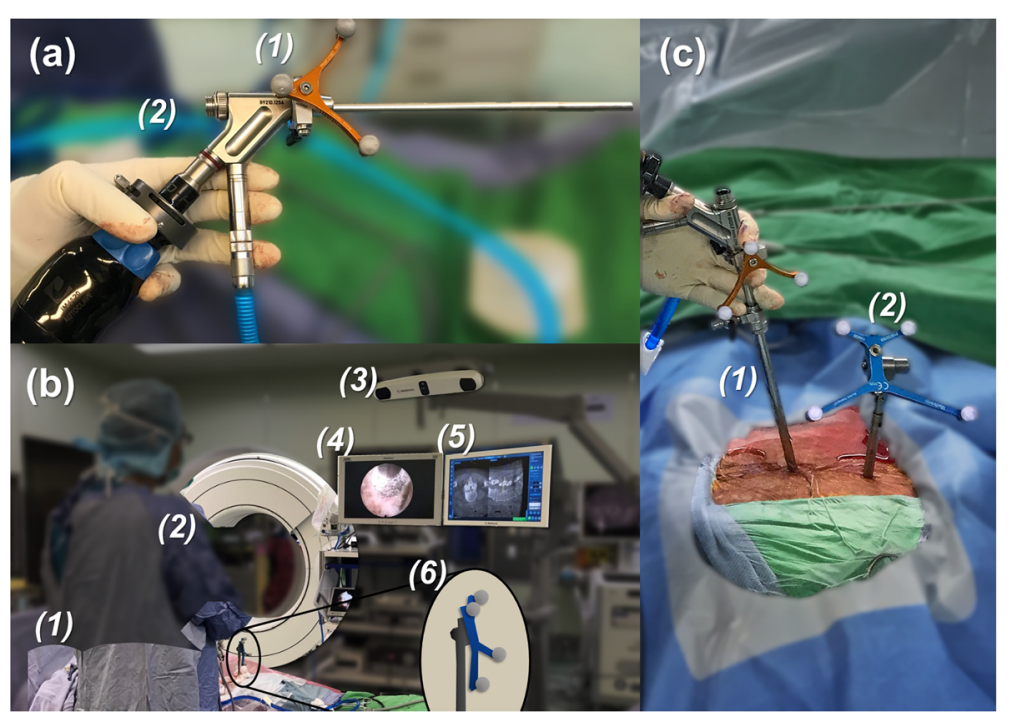

Fig. 3 a Intraoperative photo shows the attachment of (1) SureTrak ${ }^{\otimes}$ || Universal Tracker, Small Passive Fighter to the (2) Vertebris ${ }^{\circledR}$ Spine Endoscope. b Photos reveals the setting of surgery, including (1) patient positioning, (2) (3) O-arm setting, (4) endoscope monitoring, (5) navigation monitoring and (6) reference pin position. (c) Photo shows the relative position of (1) the endoscope in the sleeve, and (2) the percutaneous reference pin (in the area over the iliac crest) 


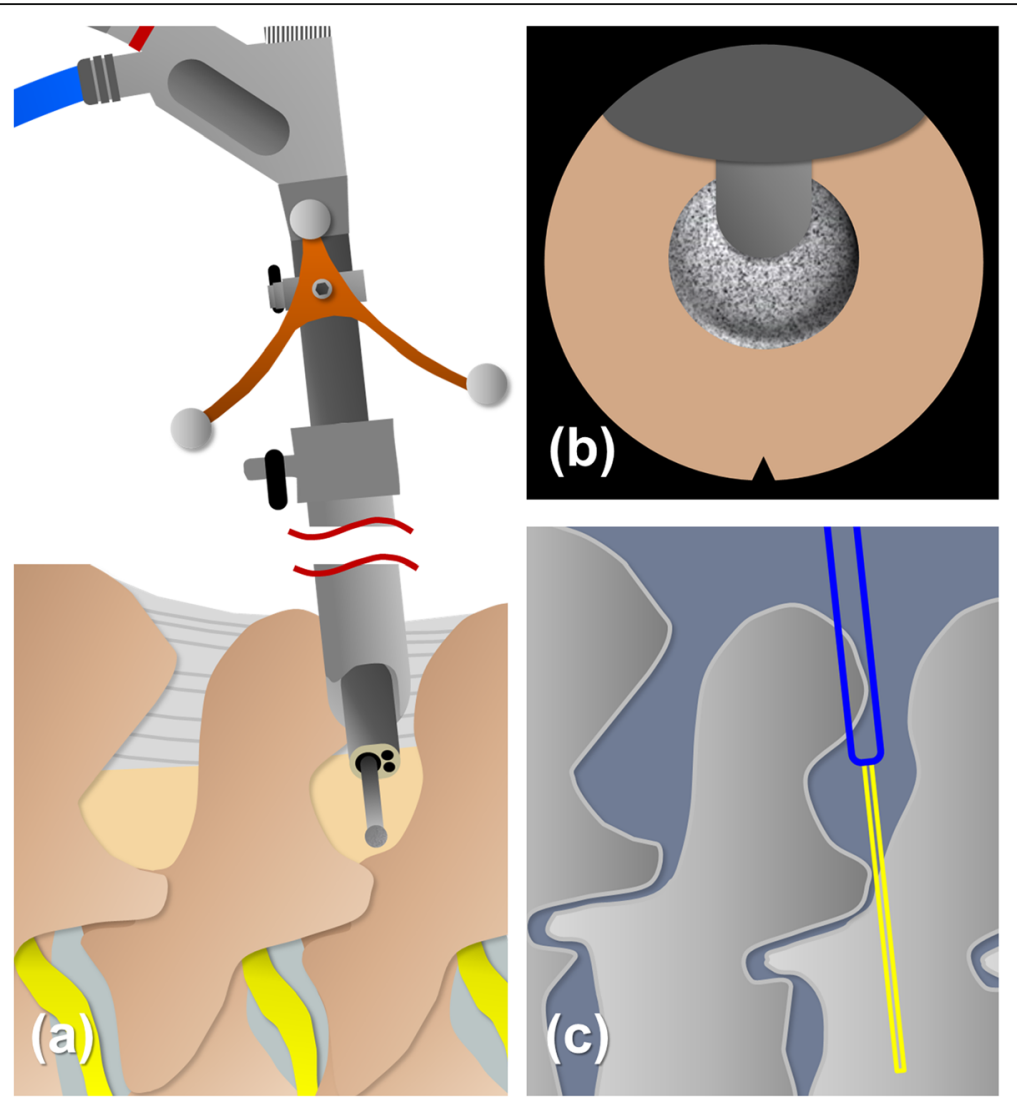

Fig. 4 Pattern diagram shows (a) the navigational instrument set-up with universal tracker attached to the endoscope. The burr tip docks on the lamina. $\mathbf{b}, \mathbf{c}$ The depth of the endoscope in the working field can be simultaneously seen on the navigation monitor. The blue bar indicates the tip of endoscope and the yellow bar points out the trajectory of burr

column from instability. Not until the cranial, caudal, medial, and lateral bony boundaries of the operative field were well prepared should the ligamentum flavum being opened. A lateral window of approximately $4-6 \mathrm{~mm}$ was made on the ligamentum flavum. The neural structures and epidural fat tissues were exposed. The perineural membrane was dissected from the neural structure carefully under direct endoscopic visualization. The operating sleeve with beveled opening could be turned and used as a nerve hook. With the joystick technique, the hypertrophic ligamentum flavum could be removed by controlling endoscope in either direction. The contralateral lateral recess decompression was achieved through unilateral approach with bilateral decompression technique. Finally, epidural bleeding was checked and well-controlled by Surgitron bipolar probe. The whole procedure was done safely and effectively under precise Oarm navigation (Fig. 6).

\section{Results}

\section{Hospital course}

Without unnecessary bone destruction, the spinal stenosis was successfully decompressed through endoscopic surgery. Average operation time was $243.5 \mathrm{~min}$ (range 154-315 min). Both the endoscopic insertion wound and the reference pin insertion wound were about $1 \mathrm{~cm}$ (Fig. 7). All patients could stand and walk freely on a walker on postoperative day 1 . The hospitalization time was within 3 days.

\section{Radiology results}

The efficacy of decompression was confirmed by MRI at 12 months follow-up post-operatively. Average dural sac cross sectional area (DSCSA) improved from 81.62 (range 67.34-89.07) to 153.27 (range 127.96-189.73) (Fig. 2) (Table 2). The follow-up X-ray performed at 12 months post-operatively showed no obvious Cobb angle change which indicated no progress of the scoliosis (Fig. 1).

\section{Clinical results}

As shown in Table 3, the mean ODI (\%) were 85 (range 82.5-90) at initial visit, 35.875 (range 25-51) at 1 month post-operatively, 26.875 (range 22.5-35) at 6 months post-operatively and 22.5 (range 17.5-30) at 12 months post-operatively $(p<0.05)$. The mean VAS score were 9 


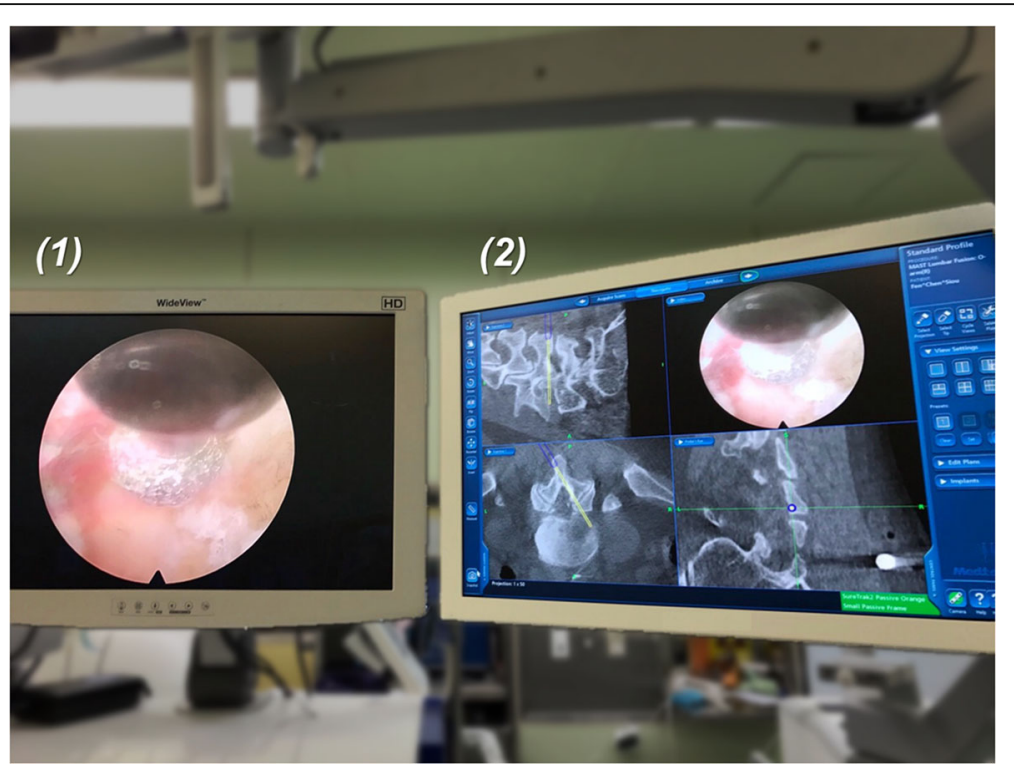

Fig. 5 Combining (1) Endoscopic images and (2) O-arm navigation images, the trajectory of the burr is navigated. The depth of burr could be adjusted precisely during laminotomy under 3D real-time O-arm navigation

(range 8-10) at initial visit, 2.25 (range 2-3) at 1 month post-operatively, 1.75 (range 1-2) at 6 months postoperatively and 0.25 (range $0-1$ ) at 12 months postoperatively $(p<0.05)$. There was no surgery-related complication such as inadequate decompression, dural tear, iatrogenic neurological injury, substantial blood loss unnecessary bone destruction with iatrogenic instability.

\section{Discussion}

To the best of our knowledge, this is the first clinical study utilizing the technique of percutaneous endoscope with $\mathrm{O}$-arm navigation to treat spinal stenosis for kyphoscoliosis patients. The advantages of this combined technique are high precision with promising decompression effect, minimal invasive surgery with little soft tissue damage, and preservation of original spinal stability.

Recent studies have demonstrated that in patients whose primary complain are radiculopathy with an underlying biomechanically stable spine, decompression surgery alone with a less invasive technique may be sufficient. Decompression with fusion does not appear to be more effective than decompression alone when considering pain relief, walking ability, or disability status [21, 22].

The gold standard method of the decompression of lumbar spinal stenosis is laminectomy with or without lateral recess and foraminal decompression. A

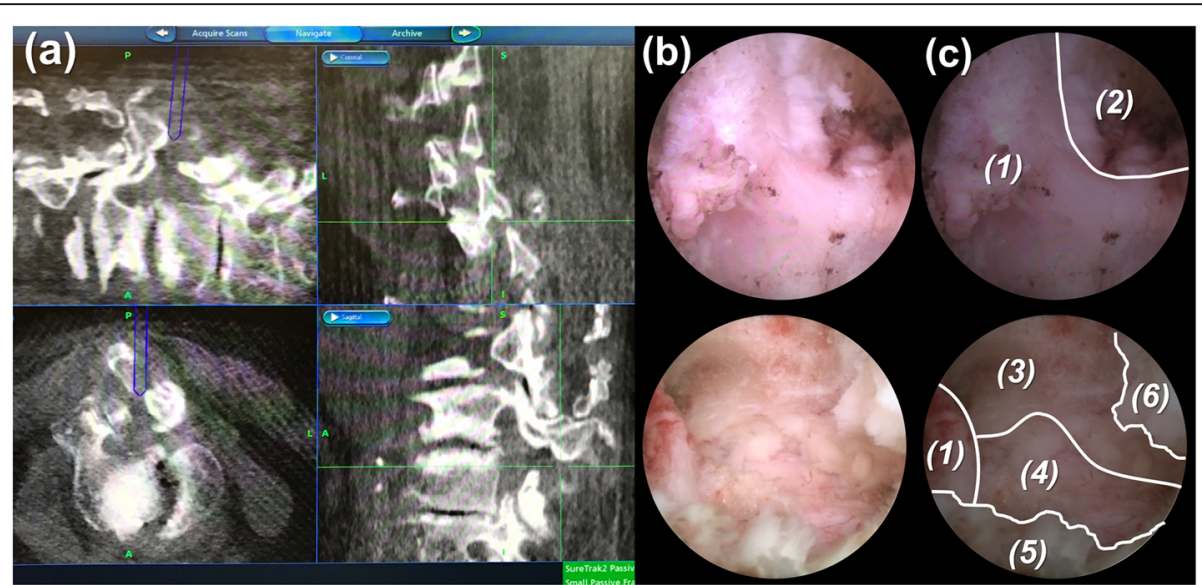

Fig. 6 Surgeon performs endoscopic laminotomy under precise O-arm navigation. Intraoperative photos show a O-arm navigation images $\mathbf{b}$ Endoscopic images and $\mathbf{c}$ its introduction: (1) base of spinous process, (2) interlaminar space, (3) right side lateral recess, (4) dura, (5) left side lateral recess, (6) ligamentum flavum 


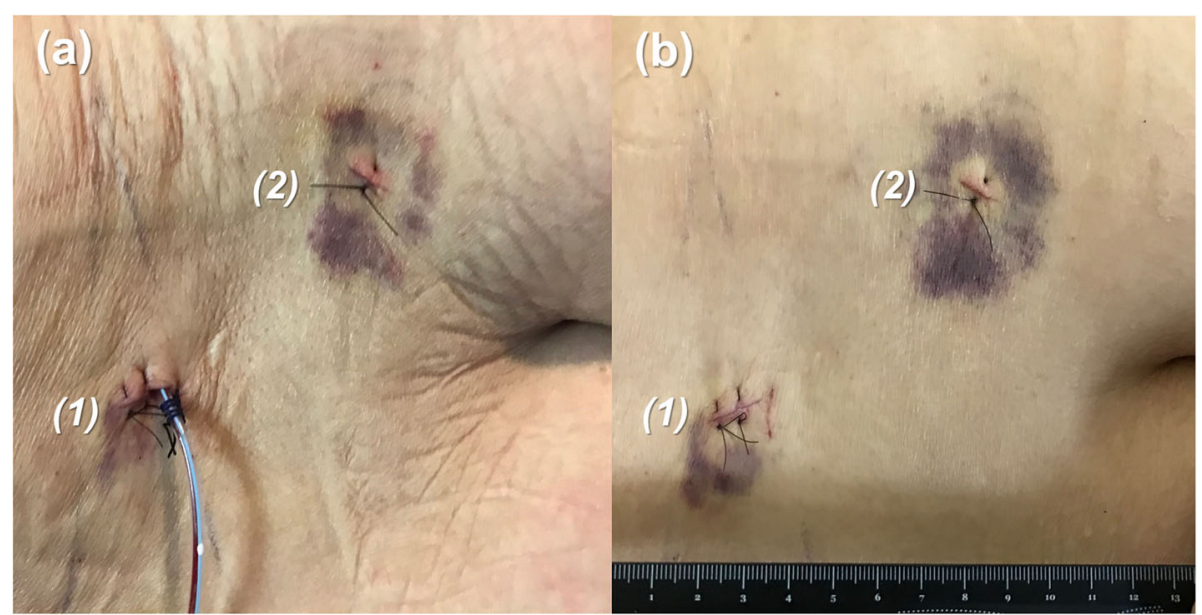

Fig. 7 a Surgical wounds on postoperative day 1 with a hemovac drainage in the endoscope insertion wound; b Both (1) the endoscope insertion wound and (2) the percutaneous reference pin insertion wound are about $1 \mathrm{~cm}$

laminectomy removes the entire lamina and the underlying ligamentum flavum, while a laminotomy removes only a small bone window from the lamina, unilaterally or bilaterally, which could be accomplished through minimally invasive surgery, such as percutaneous endoscope technique [23, 24]. Minimally invasive decompression plays an important role for elderly patients. For elderly patients with focal lumbar spinal stenosis, outcomes and surgical morbidity have been shown to be similar to those in the younger demographics [25].

Several studies have focused on the efficacy of percutaneous endoscopic surgery for spinal stenosis. Ito et al. demonstrated improved VAS, ODI and Japanese Orthopedic Association (JOA) score after conducting endoscopic decompression with sublaminar approach [26]. Kang et al. compared biportal endoscopic surgery with microscopic surgery and found that there was shorter hospitalization time, shorter operation time, less hemovac drainage and less opioid use in endoscopic surgery group [27]. Kim and Choi found satisfactory results at minimum 2-year follow-up with no wound infection or segmental spinal instability after conducting endoscopic decompression for lumbar spinal stenosis [28]. Qin et al. reported there was lower access time with navigated percutaneous endoscopic lumbar discectomy compared with conventional techniques [29]. Comparative analysis between microscopic, tubular and endoscopic decompression also discovered that tubular and endoscopic surgery group showed less invasiveness with less increase of serum CPK enzyme level, shorter hospitalization time, and less immediate postoperative back pain [30]. The efficacy and safety of endoscopic decompression have been thoroughly investigated.

The original treatment plan for our patients was open surgery and correction of scoliosis with long fusion to sacrum (in order to avoid fusion above the apex of curve) with laminectomy. However, the adverse effect of long fusion brings certain early perioperative complications in old age patients with multiple comorbidities [31]. Therefore, decompression alone using percutaneous endoscope seemed to be a reasonable alternative. Decompression alone with laminectomy may lead to iatrogenic instability. However, with accurate $\mathrm{O}$-arm guided navigated decompression, excessive bone removal could be successfully avoided. The $\mathrm{O}$-arm navigation monitor could give a warning image before the facet joint is violated. With this combined technique, it was possible to overcome abnormal anatomical challenges [32, 33]. Decompression alone in old patients with multiple comorbidities was difficult to achieve adequate decompression without unnecessary bony destruction. Oarm navigation provided a new option for this kind of patients. With $\mathrm{O}$-arm navigation, this technique could be applied in even more complicated cases, particularly in the elderly or immunocompromised patients, as well as in patients with multiple comorbidities [34].

However, the technique still carries some disadvantages. To begin with, additional wound is needed for reference pin placement. Then, there is prolonged anesthesia and surgical time due to individual surgical instrument registration with the navigation system. Furthermore, it is essential to assure the reference frame not being bumped to avoid navigation inaccuracy. The need to keep the tracking tools in line with the navigation system, will incur some restraints on the surgeon's movements during decompression steps thus further adding to surgical time. Finally, operative manipulation of endoscope and relevant instruments requires delicate surgical skills due to the limited operative field. 
The present study has some limitations. For one thing, there are a limited number of patients with no control group for comparison. For another, the follow-up is relative short, lacking long-term follow-up data. However, the purpose of this study is to describe the combined technique and assess its clinical and radiological results. Decompression alone using endoscope under O-arm navigation could be considered in patients with multiple comorbidities who could not endure major surgery and surgery-related hazardous complication.

\section{Conclusions}

To the best of our knowledge, this is the first preliminary study of percutaneous endoscopic laminotomy under $\mathrm{O}$-arm navigation with successful outcomes. Percutaneous endoscopic laminotomy under $\mathrm{O}$-arm navigation is a minimal invasive procedure compared to open posterior surgery, such as decompression surgery plus fusion surgery, with no excessive bone and soft tissue destruction, smaller cosmetic wound, shorter hospitalized duration, but similar treatment effects. We believe this novel technique is promising for spinal stenosis patients with lumbar kyphoscoliosis and multiple comorbidities. Further studies on larger sample are required to support these preliminary results.

\section{Abbreviations}

BMI: Body Mass Index; 3D: Three-Dimensional; AP: Anteroposterior; CT: Computed Tomography; MRI: Magnetic Resonance Imaging; T2WI: T2Weighted Image; ODI: Oswestry Disability Index (\%); VAS: Visual Analogue Scale; JOA: Japanese Orthopedic Association

\section{Acknowledgments}

None.

\section{Authors' contributions}

HTC, YJC and CCC participated in the design of the study. CCC was responsible for performing the clinical procedures. TYH and CWL contributed to manuscript drafting. CWL, YSL and PHH contributed to data collection. CWL, CSL, PCC and HKT contributed to manuscript editing. All authors read and approved the final manuscript.

\section{Funding}

The authors received no specific funding for this work.

\section{Availability of data and materials}

The datasets used and analyzed during the current study are available from the corresponding author on reasonable request.

\section{Ethics approval and consent to participate}

This research did not increase the risk and economic burden of patients, the patients' rights were fully protected, and the project design was conducted in line with scientific and ethical principles. This study was approved by China Medical University \& Hospital Research Ethics Committee (reference number: 1673) (CMUH107-REC2-173). All participants in this study have provided informed written consent prior to enrollment.

\section{Consent for publication}

Not applicable.

\section{Competing interests}

The authors declare that they have no competing interests.

\section{Author details}

'Department of Orthopedic Surgery, China Medical University Hospital, China Medical University, No. 2, Xueshi Rd., North Dist, Taichung City 404, Taiwan. ${ }^{2}$ Spine Center, China Medical University Hospital, China Medical University, No. 2, Xueshi Rd., North Dist, Taichung City 404, Taiwan. ${ }^{3}$ Biological Science and Technology, National Chiao Tung University, No. 75, Bo'ai St., East Dist, Hsinchu City 300, Taiwan. ${ }^{4}$ Biomedical Science and Engineering, National Chiao Tung University, No. 75, Bo'ai St., East Dist, Hsinchu City 300, Taiwan. ${ }^{5}$ Department of Sports Medicine, College of Health Care, China Medical University, No. 91, Xueshi Rd., North Dist, Taichung City 404, Taiwan. ${ }^{6}$ Department of Orthopedic Surgery, School of Medicine, China Medical University, No. 91, Xueshi Rd., North Dist, Taichung City 404, Taiwan. ${ }^{7}$ Section of Orthopedic Surgery, Department of Surgery, Ministry of Health and Welfare, Changhua Hospital, No. 80, Sec. 2, Zhongzheng Rd., Puxin Township, Changhua County 513, Taiwan. ${ }^{8}$ Functional Neurosurgery Division, Neurological Institute, Taichung Veterans General Hospital, No. 1650, Sec. 4, Taiwan Blvd., Xitun Dist, Taichung City 407, Taiwan. ${ }^{9}$ Department of Rehabilitation, Jen-Teh Junior College of Medicine, Nursing and Management, No. 79-9 Sha-Luen Hu Xi-Zhou Li Hou-Loung Town, Miaoli County 356, Taiwan.

Received: 5 July 2020 Accepted: 26 October 2020

Published online: 10 November 2020

\section{References}

1. Weinstein JN, Tosteson TD, Lurie JD, Tosteson AN, Blood E, Hanscom B, Herkowitz H, Cammisa F, Albert T, Boden SD, et al. Surgical versus nonsurgical therapy for lumbar spinal stenosis. N Engl J Med. 2008;358(8): 794-810.

2. Davis N, Hourigan $\mathrm{P}$, Clarke A. Transforaminal epidural steroid injection in lumbar spinal stenosis: an observational study with two-year follow-up. Br J Neurosurg. 2017;31(2):205-8.

3. Ammendolia C, Stuber K, de Bruin LK, Furlan AD, Kennedy CA, Rampersaud YR, Steenstra IA, Pennick V. Nonoperative treatment of lumbar spinal stenosis with neurogenic claudication: a systematic review. Spine. 2012; 37(10):E609-16.

4. Friedly $J \mathrm{~L}$, Comstock BA, Turner JA, Heagerty PJ, Deyo RA, Sullivan SD, Bauer Z, Bresnahan BW, Avins AL, Nedeljkovic SS, et al. A randomized trial of epidural glucocorticoid injections for spinal stenosis. N Engl J Med. 2014; 371(1):11-21.

5. Resnick DK, Watters WC 3rd, Sharan A, Mummaneni PV, Dailey AT, Wang JC, Choudhri TF, Eck J, Ghogawala Z, Groff MW, et al. Guideline update for the performance of fusion procedures for degenerative disease of the lumbar spine. Part 9: lumbar fusion for stenosis with spondylolisthesis. J Neurosurg Spine. 2014;21(1):54-61.

6. Lurie JD, Tosteson TD, Tosteson A, Abdu WA, Zhao W, Morgan TS, Weinstein JN. Long-term outcomes of lumbar spinal stenosis: eight-year results of the spine patient outcomes research trial (SPORT). Spine. 2015; 40(2):63-76

7. Pearson A, Blood E, Lurie J, Abdu W, Sengupta D, Frymoyer JW, Weinstein J. Predominant leg pain is associated with better surgical outcomes in degenerative spondylolisthesis and spinal stenosis: results from the spine patient outcomes research trial (SPORT). Spine. 2011;36(3):219-29.

8. Pearson A, Blood E, Lurie J, Tosteson T, Abdu WA, Hillibrand A, Bridwell K, Weinstein J. Degenerative spondylolisthesis versus spinal stenosis: does a slip matter? Comparison of baseline characteristics and outcomes (SPORT). Spine. 2010;35(3):298-305.

9. Ahmad S, Hamad A, Bhalla A, Turner S, Balain B, Jaffray D. The outcome of decompression alone for lumbar spinal stenosis with degenerative spondylolisthesis. Eur Spine J. 2017;26(2):414-9.

10. Austevoll IM, Gjestad R, Brox Jl, Solberg TK, Storheim K, Rekeland F, Hermansen E, Indrekvam K, Hellum C. The effectiveness of decompression alone compared with additional fusion for lumbar spinal stenosis with degenerative spondylolisthesis: a pragmatic comparative non-inferiority observational study from the Norwegian registry for spine surgery. Eur Spine J. 2017;26(2):404-13.

11. Chang W, Yuwen P, Zhu Y, Wei N, Feng C, Zhang Y, Chen W. Effectiveness of decompression alone versus decompression plus fusion for lumbar spinal stenosis: a systematic review and meta-analysis. Arch Orthop Trauma Surg. 2017;137(5):637-50. 
12. Ghogawala Z, Dziura J, Butler WE, Dai F, Terrin N, Magge SN, Coumans JV, Harrington JF, Amin-Hanjani S, Schwartz JS, et al. Laminectomy plus fusion versus laminectomy alone for lumbar Spondylolisthesis. N Engl J Med. 2016; 374(15):1424-34.

13. Forsth $P$, Olafsson $G$, Carlsson $T$, Frost A, Borgstrom F, Fritzell P, Ohagen $P$, Michaelsson K, Sanden B. A randomized, controlled trial of fusion surgery for lumbar spinal stenosis. N Engl J Med. 2016;374(15):1413-23.

14. Li X, Han Y, Di Z, Cui J, Pan J, Yang M, Sun G, Tan J, Li L. Percutaneous endoscopic lumbar discectomy for lumbar disc herniation. J Clin Neurosci. 2016;33:19-27

15. Ahmed SI, Javed G, Bareeqa SB, Shah A, Zubair M, Avedia RF, Rahman N, Samar SS, Aziz K. Comparison of decompression alone versus decompression with fusion for Stenotic lumbar spine: a systematic review and meta-analysis. Cureus. 2018;10(8):e3135.

16. Donnarumma P, Tarantino R, Nigro L, Rullo M, Messina D, Diacinti D, Delfini R. Decompression versus decompression and fusion for degenerative lumbar stenosis: analysis of the factors influencing the outcome of back pain and disability. J Spine Surg. 2016;2(1):52-8.

17. Lin CW, Chang CC, Chen HT, Chen YJ, Lin CS, Hsu HC, Tsou HK. 3D real-time image-guided navigation spine Corpectomy with ultrasonic bone cutter: technical note. World Neurosurg. 2020;135:197-204.

18. Baaj AA, Beckman J, Smith DA. O-arm-based image guidance in minimally invasive spine surgery: technical note. Clin Neurol Neurosurg. 2013;115(3):342-5.

19. Rahmathulla G, Nottmeier EW, Pirris SM, Deen HG, Pichelmann MA. Intraoperative image-guided spinal navigation: technical pitfalls and their avoidance. Neurosurg Focus. 2014;36(3):E3.

20. Terran J, Schwab F, Shaffrey Cl, Smith JS, Devos P, Ames CP, Fu KM, Burton D, Hostin R, Klineberg E, et al. The SRS-Schwab adult spinal deformity classification: assessment and clinical correlations based on a prospective operative and nonoperative cohort. Neurosurgery. 2013;73(4):559-68.

21. Omidi-Kashani F, Hasankhani EG, Ashjazadeh A. Lumbar spinal stenosis: who should be fused? An updated review. Asian Spine J. 2014:8(4):521-30.

22. Thomas K, Faris P, Mclntosh G, Manners S, Abraham E, Bailey CS, Paquet J, Cadotte D, Jacobs WB, Rampersaud YR, et al. Decompression alone vs. decompression plus fusion for claudication secondary to lumbar spinal stenosis. Spine J. 2019:19(10):1633-9.

23. Alimi M, Hofstetter CP, Pyo SY, Paulo D, Hartl R. Minimally invasive laminectomy for lumbar spinal stenosis in patients with and without preoperative spondylolisthesis: clinical outcome and reoperation rates. J Neurosurg Spine. 2015;22(4):339-52

24. Nerland US, Jakola AS, Solheim O, Weber C, Rao V, Lonne G, Solberg TK, Salvesen O, Carlsen SM, Nygaard OP, et al. Minimally invasive decompression versus open laminectomy for central stenosis of the lumbar spine: pragmatic comparative effectiveness study. Bmj. 2015;350:h1603.

25. Aleem IS, Rampersaud YR. Elderly patients have similar outcomes compared to younger patients after minimally invasive surgery for spinal stenosis. Clin Orthop Relat Res. 2014;472(6):1824-30.

26. Ito F, Ito Z, Shibayama M, Nakamura S, Yamada M, Yoshimatu H, Takeuchi M, Shimizu K, Miura Y. Step-by-step sublaminar approach with a newlydesigned spinal endoscope for unilateral-approach bilateral decompression in spinal stenosis. Neurospine. 2019;16(1):41-51.

27. Li XF, Jin LY, Lv ZD, Su XJ, Wang K, Shen HX, Song XX. Efficacy of percutaneous transforaminal endoscopic decompression treatment for degenerative lumbar spondylolisthesis with spinal stenosis in elderly patients. Exp Therapeutic Med. 2020;19(2):1417-24

28. Kim JE, Choi DJ. Clinical and radiological outcomes of unilateral Biportal endoscopic decompression by 30 degrees arthroscopy in lumbar spinal stenosis: minimum 2-year follow-up. Clin Orthop Surg. 2018;10(3):328-36.

29. Qin H, Huang S, Xu L, Wei P, Jiang J, Xie Z, Luo X, Tan H, Huang W. Radiation exposure and operation time in percutaneous endoscopic lumbar discectomy using fluoroscopy-based navigation system. World Neurosurg. 2019;127:e39-48

30. Lee C-W, Yoon K-J, Ha S-S. Comparative analysis between three different lumbar decompression techniques (microscopic, tubular, and endoscopic) in Lumbar Canal and lateral recess stenosis: preliminary report. Biomed Res Int. 2019;2019:1-11.

31. Cho KJ, Suk SI, Park SR, Kim JH, Kim SS, Lee TJ, Lee JJ, Lee JM. Short fusion versus long fusion for degenerative lumbar scoliosis. Eur Spine J. 2008;17(5):650-6.

32. Schouten R, Lee R, Boyd M, Paquette S, Dvorak M, Kwon BK, Fisher C, Street J. Intra-operative cone-beam CT (O-arm) and stereotactic navigation in acute spinal trauma surgery. J Clin Neurosci. 2012;19(8):1137-43.
33. Ammirati M, Salma A. Placement of thoracolumbar pedicle screws using Oarm-based navigation: technical note on controlling the operational accuracy of the navigation system. Neurosurg Rev. 2013;36(1):157-62 discussion 162

34. Li X, Zhang F, Zhang W, Shang X, Han J, Liu P. A new method to precisely control the depth of percutaneous screws into the pedicle by counting the rotation number of the screw with low radiation exposure: technical note. Eur Spine J. 2017;26(3):750-3.

\section{Publisher's Note}

Springer Nature remains neutral with regard to jurisdictional claims in published maps and institutional affiliations.
Ready to submit your research? Choose BMC and benefit from:

- fast, convenient online submission

- thorough peer review by experienced researchers in your field

- rapid publication on acceptance

- support for research data, including large and complex data types

- gold Open Access which fosters wider collaboration and increased citations

- maximum visibility for your research: over $100 \mathrm{M}$ website views per year

At BMC, research is always in progress.

Learn more biomedcentral.com/submissions 